\title{
Peripheral motor nerve conduction in elderly demented and non-demented psychiatric patients
}

\author{
RAYMOND LEVY AND ELMAN W. POOLE \\ From the Institute of Psychiatry, Maudsley Hospital, London
}

The changes in the nervous system associated with ageing and their relationship to mental illness have long attracted interest. While much attention has been focused on the study of the central nervous system of patients suffering from dementia in old age such studies have generally ignored the condition of the peripheral nervous system. In the study of ageing processes and associated clinical disorders it is worth considering whether abnormalities in one part of a body system occur in relative isolation or are associated with multiple defects elsewhere in the same or other systems. In this way it may be possible to define the contribution of both general and specific disturbing factors to the various clinical syndromes associated with ageing. For example, in nervous illness the dementia of elderly patients might result from some special selective disturbance in an otherwise intact and well-preserved nervous system, or alternatively, it might merely represent one prominent facet of disturbance in a nervous system with multiple widespread defects arising from a generalized disruptive process.

In this study an attempt has been made to determine whether patients with central nervous abnormalities manifest as senile or arteriosclerotic dementia showed evidence also of peripheral nerve dysfunction and differed from non-demented aged patients in this respect. Patients with functional psychosis were chosen for comparison with demented patients because of their availability in a similar hospital setting and the clinical relevance of this comparison. In this initial study assessment of peripheral nerve function had to be restricted to measurements of the maximum motor conduction velocity in the median nerve of the forearm because of practical difficulties.

\section{MATERIAL AND METHODS}

Subjects were obtained from two hospitals thereby providing two series for comparison, as set out in Table I.

Present address: E.E.G. Department, Churchill Hospital, Oxford.
B SERIES These subjects came from a small geriatric investigation unit at the Bethlem Royal Hospital. Eight demented and eight depressed patients were examined: the mean ages were 71.0 (S.D. 9.0) and 71.2 (S.D. 7.6) years respectively and there were three men and five women in each group.

T SERIES These subjects were from a large mental hospital with a special interest in geriatric patients (Tooting Bec Hospital). Twenty-one dements and 21 'controls' (depressives and schizophrenics) were examined: the mean ages were 73.1 (S.D. 6.7) and 73.4 (S.D. 6.8) for each group respectively, and all were men.

The demented patients in both series had unequivocab evidence of dementia based on a detailed clinical appraisab with supporting evidence from psychological tests in the $B$ series. They were considered to be suffering from senile or arteriosclerotic dementia, and no attempt was made int this study to distinguish between these two diagnoseso The patients in the $\mathrm{T}$ series were less fully documented but the dementia was always well established; indeed, the dementia in the $T$ series was generally more longstanding and more advanced than in the B series and the patients had been in hospital longer. Because of such differences, the results from each series were evaluated separately.

Both non-demented 'control' groups consisted of patients diagnosed as having functional psychoses and considered clinically to have no evidence of significant organic disorder: In each series they were matched in age and sex with the demented patients since there is evidence to suggest that maximum conduction velocity decreases with advancing years and that values are slightly lower in men than in women (Wagman and Lesse, 1952; and Norris, Shock, and Wagman, 1953).

At the outset it was decided to exclude patients on the following grounds: (1) those with a history or signs of overt peripheral neuropathy other than absent ankle jerks; (2) those who were bedridden or ill in other respects; (3) those suffering from metabolic or toxic disorders likely to affect peripheral nerve function, or those known to have had a grossly inadequate diet. Four patients were excluded in this way. Drug administration presented a problem since it was considered unjustifiable to disturb drug regimes for this study. However, in the B series all patients were tested before having drug therapy, and in the $T$ series the drugs employed (pheno- 
thiazines or antidepressants) are not known to depress peripheral nerve function.

After the patients had been examined clinically from both physical and psychiatric viewpoints conduction velocity measurements were made in the median nerve, this nerve being chosen because of its reduced vulnerability to trauma. The technique used was a modification of that described by Simpson (1956), Thomas, Sears, and Gilliat (1959), and Gilliatt and Thomas (1960). The right median nerve was stimulated at the wrist and above the elbow by square wave pulses of $1.5 \mathrm{msec}$. duration produced by a Medelec EMG-stimulator unit with an output impedance of $1,000 \mathrm{ohms}$ at a maximum output of 180 volts (no load). These stimuli were administered through silver discs set $3 \mathrm{~cm}$. apart in a perspex plate and covered by lint pads kept moist with normal saline. This plate was strapped over the median nerve with the cathode placed distally, and supramaximal stimuli were applied at the rate of $1 / \mathrm{sec}$., efforts being made to obtain the same shape of muscle potential response from stimulation at both wrist and elbow.

Muscle potentials were recorded from the abductor pollicis brevis muscle using surface electrodes of the usual chlorided silver cup variety $1 \mathrm{~cm}$. in diameter and filled with Cambridge electrode jelly. One electrode was strapped over the muscle belly and the other over the muscle tendon. A surface plate was strapped as an earth between the stimulating and recording electrodes.

Muscle potentials were displayed on a twin-beam oscilloscope, one beam providing a millisecond time marker. The traces were photographed from a monitor screen, at least 10 traces being superimposed at any one stimulation site. Latencies were measured from the stimulus artefact to the first muscle potential deflection at both stimulation sites and the maximum forearm conduction velocity calculated from the difference in these latencies and the distance between the stimulation sites measured along the surface of the limb. An example of the results obtained is shown in Figure 1. All the tests were carried out in a warm room and the patients' arms were immersed in hot water for five minutes beforehand. More extensive tests, e.g., involving both median and ulnar nerves bilaterally, and including lower limb assessments and reflex and sensory functions, had to be abandoned in view of the difficulties encountered in prolonged testing of demented patients.

Latency and conduction velocity data for each group were compared statistically using analysis of variance; correlation coefficients were calculated for both conduction velocity and wrist latency with respect to age, and also for forearm conduction velocity with respect to wrist latency.

\section{RESULTS}

The essential findings are shown in Fig. 2 and Table I. In Fig. $2 \mathrm{a}$ forearm conduction velocity has been plotted against the age of the patient in each of the two dement and control series; in both series the majority of the dement patients having slower forearm conduction velocities, fall to the left of the control patients. However, this is not the case with the latencies of the muscle response following wrist stimulation which appear plotted in the same way against age in Fig. 2b with the same groupings and symbols.

The actual mean values and standard deviation for each group are shown in Table I. Statistical analysis confirmed that: (1) mean conduction velocities in both dementia groups were lower than in both control groups ( $\mathrm{P}<0.01$ for $\mathrm{B} ; \mathbf{P}<0.001$ for $\mathrm{T})$; (2) the $\mathrm{T}$ dementia group had a substantially
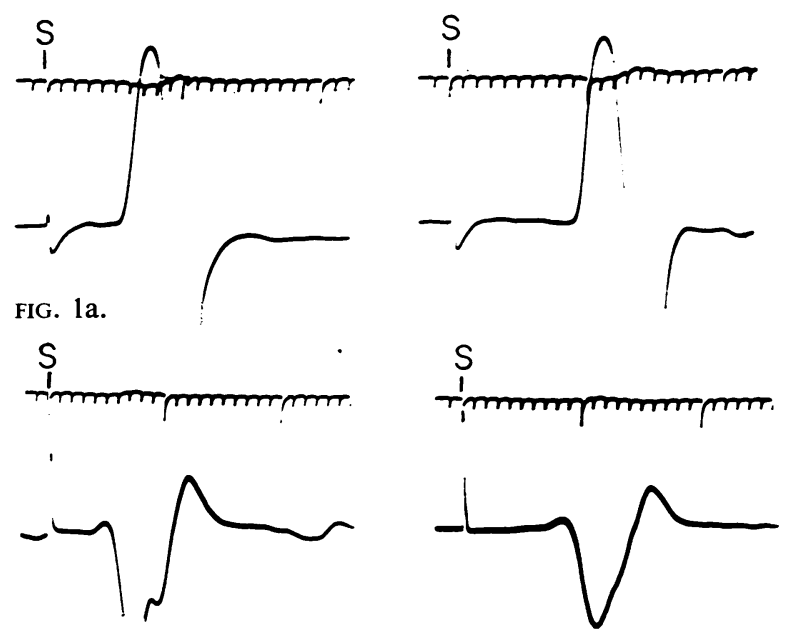

FIG. $1 b$.
FIG. 1a. Recordings from abductor pollicis brevis muscle following stimulation (single) of median nerve at wrist and at elbow in a demented patient aged 65. $S$ indicates stimulation: $1 \mathrm{msec}$. and 10 msec. time marker; $300 \mu \mathrm{V}$ calibration. (Latency at wrist and elbow $5 \mathrm{msec}$. and 9 msec. respectively; interstimulation distance $15.3 \mathrm{~cm}$.; conduction velocity 38 metres/second.) FIG. 1b. Similar recordings in a Trmmm control non-demented psychiatric patient aged 65. Time marke
calibration as for Fig. 1a. (Latency at wrist and elbow 3.5 msec. and 7 msec. respectively; interstimulation distance $16.3 \mathrm{~cm}$.; conduction velocity 47 metres/second.) Waveform differences compared with Fig. la are of no significance. 
TABLE I

AGE AND CONDUCTION VELOCITY DATA IN DEMENTED AND NON-DEMENTED CONTROL SUBJECTS

\begin{tabular}{|c|c|c|c|c|c|c|c|c|c|c|}
\hline \multirow[t]{3}{*}{ Series } & \multirow[t]{3}{*}{ No. } & \multirow{2}{*}{\multicolumn{2}{|c|}{$\operatorname{Age}(y r)}}$. & \multirow{2}{*}{\multicolumn{2}{|c|}{$\begin{array}{l}\text { Forearm Conduction } \\
\text { Velocity } \\
\text { (metres } / \text { sec.) }\end{array}$}} & \multirow{2}{*}{\multicolumn{2}{|c|}{$\begin{array}{l}\text { Wrist Latency } \\
(\text { msec.) }\end{array}$}} & \multicolumn{3}{|c|}{ Correlation Coefficients $(r)$} \\
\hline & & & & & & & & \multirow{2}{*}{$\begin{array}{l}\text { Age/Conduction } \\
\text { Velocity }\end{array}$} & \multirow[t]{2}{*}{ Age/Latency } & \multirow{2}{*}{$\begin{array}{l}\text { Conduction } \\
\text { Velocity/Latency }\end{array}$} \\
\hline & & Mean & S.D. & Mean & S.D. & Mean & S.D. & & & \\
\hline $\begin{array}{l}\text { B controls } \\
\text { B dements }\end{array}$ & $\begin{array}{l}8 \\
8\end{array}$ & $\begin{array}{l}71 \cdot 2 \\
71 \cdot 0\end{array}$ & $\begin{array}{l}7 \cdot 6 \\
9 \cdot 0\end{array}$ & $\begin{array}{l}59 \cdot 4 \\
50 \cdot 1\end{array}$ & $\begin{array}{l}4 \cdot 7 \\
5 \cdot 2\end{array}$ & $\begin{array}{l}3 \cdot 8 \\
4 \cdot 2\end{array}$ & $\begin{array}{l}0.8 \\
0.7\end{array}$ & & & $\begin{array}{l}+0.16 \\
+0.32\end{array}$ \\
\hline $\begin{array}{l}\text { T controls } \\
\mathrm{T} \text { dements }\end{array}$ & $\begin{array}{l}21 \\
21\end{array}$ & $\begin{array}{l}73 \cdot 4 \\
73 \cdot 1\end{array}$ & $\begin{array}{l}6 \cdot 8 \\
6 \cdot 7\end{array}$ & $\begin{array}{l}55 \cdot 4 \\
38 \cdot 4\end{array}$ & $\begin{array}{l}6 \cdot 1 \\
5 \cdot 4\end{array}$ & $\begin{array}{l}4 \cdot 4 \\
4 \cdot 4\end{array}$ & $\begin{array}{l}0.9 \\
0.8\end{array}$ & & & $\begin{array}{l}-0.09 \\
+0.45\end{array}$ \\
\hline $\begin{array}{l}\text { Total controls } \\
\text { Total dements }\end{array}$ & $\begin{array}{l}29 \\
29\end{array}$ & $\begin{array}{l}72 \cdot 8 \\
72 \cdot 6\end{array}$ & $\begin{array}{l}7.0 \\
6 \cdot 6\end{array}$ & $\begin{array}{l}56.5 \\
41.6\end{array}$ & $\begin{array}{l}6 \cdot 1 \\
7 \cdot 5\end{array}$ & $\begin{array}{l}4 \cdot 2 \\
4 \cdot 4\end{array}$ & $\begin{array}{l}0.9 \\
0.8\end{array}$ & $\begin{array}{l}+0.07 \\
+0.20\end{array}$ & $\begin{array}{l}+0.14 \\
+0.21\end{array}$ & $\begin{array}{l}-0.12 \\
+0 \cdot 19\end{array}$ \\
\hline Grand total & 58 & $72 \cdot 7$ & $6 \cdot 8$ & $49 \cdot 1$ & $10 \cdot 1$ & $4 \cdot 3$ & 0.9 & $+0 \cdot 10$ & $+0 \cdot 18$ & -0.04 \\
\hline
\end{tabular}

lower mean conduction velocity than the B group (P $<0.001)$; (3) the $\mathrm{T}$ control group had only a slightly lower mean conduction velocity than the B control group (P>0.1); (4) the wrist latencies in contrast showed only slight differences between each of the groups ( $P$ values $>0 \cdot 1$ ). These results appeared internally consistent in that the wrist latencies were shortest in the B controls who had the fastest conduction velocities, whereas the latencies were slightly longer in both dementia series than in their respective controls. In both series it was noteworthy that there was no suggestion of a much wider scatter of values in any one group such as might occur if the differences were dependent on gross lesions in a few patients.

In view of the reported correlation between age and motor nerve conduction (Wagman and Lesse, 1952; Norris et al., 1953) correlation coefficients were calculated for age in relation to forearm conduction and also to wrist latency. These all gave small positive values (see Table I) none being statistically significant. It is noteworthy that a uniform slowing in conduction velocity throughout forearm and wrist segments would, if correlated with age, result in negative coefficients for conduction velocity and positive ones for wrist latency. Correlation coefficients were also calculated for conduction velocity in relation to wrist latency on the assumption that any generalized slowing of conduction throughout the course of the nerve should produce a prolongation of the wrist latency, i.e., a negative correlation. In fact small non-significant positive and negative values were obtained except for the $\mathbb{R}$ dements where there was a positive correlation $0.45(\mathrm{P}<0.05)$.

\section{DISCUSSION}

These results suggest there is some decrease in the maximum motor conduction velocity in the median nerve of patients with dementia as compared with patients of similar age with functional psychiatric

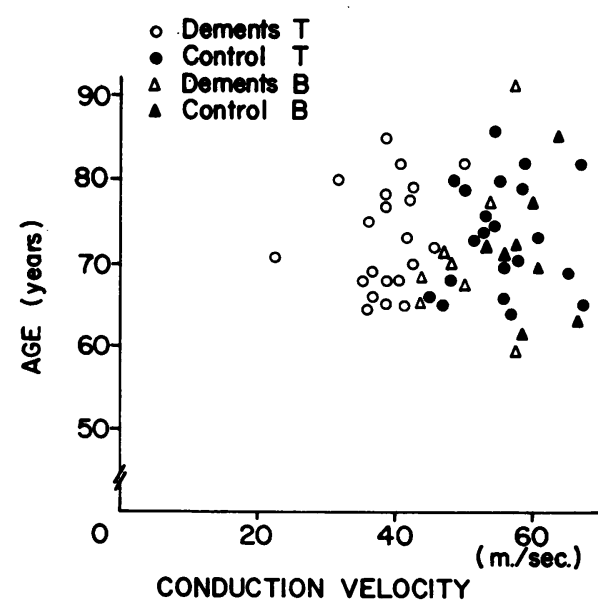

a
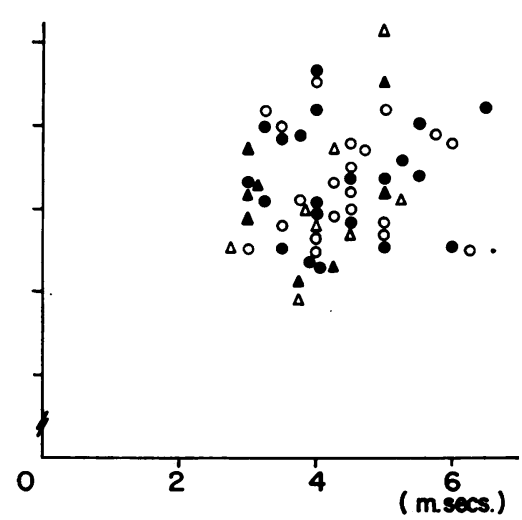

WRIST LATENCY
FIG. 2a. Conduction velocity in metres/ second plotted against age of patient for each series

FIG. 2b. Latency in msec. of muscle response following stimulation at wrist plotted against age of patient for each series as in Fig. $2 a$. 
disorder. Comparison with normal conduction values published by other workers (Thomas et al., 1959; Thomas, 1960) indicates that these psychiatric control subjects were similar to normal subjects, and that the demented patients differed correspondingly. In the present study there were no significant group differences in the latency of muscle response following stimulation at the wrist; comparison with published values is more difficult but these (Simpson, 1956; Thomas, 1960) are similar to, or slightly below, the values obtained for all groups and are most comparable with the B control figures. Thus this study in itself and in relation to previous work indicates a reduction in forearm conduction velocity most marked in the more severely demented patients, i.e., the $\mathrm{T}$ series. The failure of the wrist latency results to reveal any significant group differences might depend on the relatively short length of nerve concerned in wrist latency measurements, or on the fact that the nerve may not have been involved uniformly along its whole length. These results contrast with the findings in peripheral neuropathy.

The lack of significant correlation of conduction velocity with age is noteworthy in view of the agelinked reductions in ulnar nerve conduction reported previously over a wide age range (Wagman and Lesse, 1952; Norris et al., 1953). These workers found a $10 \%$ drop in conduction velocity over the age of 60 , but these findings have not been confirmed (Kauchtschischwili, Ramelli, and Zerbi, 1962).

In considering factors which might produce these results it is difficult to see how bias in selection of material and differences in type and ease of examination could account for these findings. Drugs, peripheral neuropathy, or undetected peripheral nerve lesions in a few patients could scarcely cause the differences. Temperature effects have to be considered. It is conceivable that demented patients might have a more precarious peripheral circulation which might result in their having colder extremities and thus slower nerve conduction. Such a factor would cause greater slowing in the more peripheral segment of the nerve, i.e., that below the wrist, an effect which was not clearly observed. There was, in fact, nothing to suggest that the temperatures were different in the dementia groups and control groups, and though actual temperatures were not measured precautions were taken to ensure uniformity. At all events, from the published data relating to normal limbs (Henricksen, 1956; Johnson and Olsen, 1960) it would seem unlikely that the usual range of limb temperature variation could account entirely for the substantial differences observed, if the temperature sensitivity of the patients' nerves were normal. The possible effects of threshold differences in fibre excitability between non-demented and demented patients have also to be considered, the demented patients perhaps having the higher thresholds for fastest conducting fibres; but here again there is no ready explanation. There was no evidence in the scatter of the values to suggest that the $T$ series was specially heterogeneous and contained a minority of unusual values. Nevertheless the significant correlation in the $\mathrm{T}$ dements between wrist latency and forearm velocity remains to be accounted for.

If it is accepted that there is some impairment of motor conduction in senile dementia then its possible relationship to the degree of dementia or duration of illness is noteworthy. There is still controversy as to whether a close relationship exists between the mental state of demented patients and the nature and extent of degeneration in the brain (Grunthal, 1927; Rothschild, 1937; Corsellis, 1962), but the weight of present evidence favours the view that the relationship is a good deal closer than it has been fashionable to believe. Comparison of the demented patients in the B series with those more seriously affected in the $T$ series suggests that a similar sort of relationship may also hold to some extent for the peripheral nerves.

It is uncertain whether the underlying involvement of large fibres is of a structural or functional nature, or whether it results from a diffuse process involving most nerves, probably on the basis of some general ageing process, or from patchy impairment perhaps due to scattered focal peripheral nerve lesions. Much more evidence can obviously be collected to ascertain the extent and nature of these defects and the degree of concordance in different parts of the nervous system. Studies of this type within the nervous system and also in relation to similar studies of other body systems may clarify the contributions of general and specific factors to the phenomena of ageing and its associated clinical disorders.

\section{SUMMARY}

Motor nerve conduction has been studied in the median nerve in two series of demented elderly patients and in two comparable control series of non-demented patients suffering from functional psychoses.

Maximum conduction velocity in the forearm and wrist latency times were obtained following electrical stimulation of the median nerve at wrist and elbow with recording surface electrodes over the abductor pollicis brevis muscle.

Maximum forearm conduction velocity was found to be significantly lower in both demented series than in control series, the differences being greater in the more severely demented patients; no similar significant group differences were found for latency values 
following wrist stimulation. No significant age correlations were found with either conduction velocity or wrist latency.

In non-demented psychiatric patients conduction velocity and wrist latency values were comparable with published normal values.

The basis for the associated peripheral and central nervous defects is discussed in relation to ageing.

We are indebted to Dr. F. Post for his encouraging interest and permission to study patients under his care. Drs. J. E. S. Lloyd and T. H. Bewley kindly assisted in making patients at Tooting Bec Hospital available for study. We are indebted to Professor G. D. Dawson and Professor D. Hill for advice and encouragement. Grants for equipment (to E.W.P.) from London University Central Research Fund and the Medical Research Council are gratefully acknowledged. The work was submitted by R.L. as part requirement for Diploma of Psychological Medicine, University of London.

\section{REFERENCES}

Corsellis, J. A. N. (1962). Mental Illness and the Ageing Brain, (Maudsley Monograph, No. 9.) Oxford University Press London.
Gilliatt, R. W., and Thomas, P. K. (1960). Changes in nerve conduction with ulnar lesions at the elbow. J. Neurol. Neurosurg. Psychiat., 23, 312-320.

Grünthal, E. (1927). Klinisch-anatomisch vergleichende Untersuchungen über den Greisenblödsinn. Z. ges. Neurol. Psychiat., 111, 763-818.

Henricksen, J. D. (1956). Conduction velocity of motor nerves in normal subjects and patients with neuromuscular disorders. M.S. Thesis (Phys. Med.), University of Minnesota.

Johnson, E. W., and Olsen, K. J. (1960). Clinical value of motor nerve conduction velocity determination. J. Amer. med. Ass., 172, 2030-2035.

Kauchtschischwili, G. M., Ramelli, E., and Zerbi, F. (1962). La vitesse de conduction du nerf cubital chez les personnes très âgées. Electroenceph. clin. Neurophysiol., Suppl. 22, pp. 21-23.

Norris, A. H., Shock, N. W., and Wagman, I. H. (1953). Age changes in the maximum conduction velocity of motor fibers of human ulnar nerves. J. appl. Physiol., 5, 589-593.

Rothschild, D. (1937). Pathologic changes in senile psychoses and their psychobiologic significance. Amer. J. Psychiat., 93, 757-788.

Simpson, J. A. (1956). Electrical signs in the diagnosis of carpal tunnel and related syndromes. J. Neurol. Neurosurg. Psychiat., 19, 275-280.

Thomas, P. K. (1960). Motor nerve conduction in the carpal tunnel syndrome. Neurology (Minneap.), 10, 1045-1050.

Thomas, P. K., Sears, T. A., and Gilliatt, R. W. (1959). The range of conduction velocity in normal motor nerve fibres to the small muscles of the hand and foot. J. Neurol. Neurosurg. Psychiat., 22, 175-181.

Wagman, I. H., and Lesse, H. (1952). Maximum conduction velocities of motor fibers of ulnar nerve in human subjects of various ages and sizes. J. Neurophysiol., 15, 235-244.

\section{The June 1966 Issue}

\section{THE JUNE 1966 ISSUE CONTAINS THE FOLLOWING PAPERS}

Platelet stickiness in multiple sclerosis J. H. D. MILLAR, J. D. MERRETT, and ANNE M. DALBY

Effects of reserpine on amino-acid excretion in patients with migraine R. W. KIMBALL and M. A. GOODMAN

Observations on stammering after localized cerebral injury R. K. JONES

An experimental study of the $F$ wave in the baboon J. G. MCLEOD and SHIRLEY H. WRAY

Ratio of maximum $\mathrm{H}$ reflex to maximum $\mathrm{M}$ response as a measure of spasticity $W$. B. MATTHEWS

Fibre size and content of the anterior tibial nerve of the foot MICHAEL SWALLOW

Effect of adrenaline, noradrenaline, atropine, and nicotine on some types of human tremor JOHN MARSHALL and HAROLD SCHNIEDEN

Dysphonia due to tremor G. ARDRAN, M. KINSBOURNE, and GEOFFREY RUSHWORTH

Nitrofurantoin and peripheral neuropathy with megaloblastic anaemia JOHN S. MORRIS

Persistent intracranial bleeding as a complication of hemispherectomy D. R. OPPENHEIMER and H. B. GRIFFITH
Fatal cerebral infarction simulating an acute expanding lesion LOUISE VAN TROTSENBURG and PIERRE J. VINKEN

Tethering of the conus medullaris within the sacrumi D. YASHON and R. A. BEATTY

Destructive effects of prolonged status epilepticus MELVIN H. EPSTEIN and JOHN S. O'CONNOR

Experimental chloroquine myopathy BARBARA SMITH and $F$. O'GRADY

A case of cerebral paragonimiasis DAVID LANDSBOROUGH

Intramedullary dermoid M. ROTH, L. HANÁK, and $R$. SCHRÖDER

Clinical trial of carbazepine (Tegretol) in trigeminal neuralgia F. G. CAMPBELL, J. G. GRAHAM, and $K$. J. ZILKHA

Cognitive abilities in relation to frequency of seizures and neuropathology of the temporal lobes in man C. B. BLAKEMORE, G. ETTLINGER, and M. A. FALCONER

Intermittent claudication and lateral lumbar disc protrusions N. C. SPANOS and J. ANDREW

Book reviews

Copies are still available and may be obtained from the PUBLISHING MANAGER, BRITISH MEDICAL ASSOCIATION, TAVISTOCK SQUARE, W.C.1., price 18s. 6D. 